\title{
MICROPROPAGATION OF NEPENTHES HYBRID (N. VIKING × N. MIRANDA) USING A TEMPORARY IMMERSION BIOREACTOR SYSTEM, SETIS ${ }^{\mathrm{TM}}$
}

\author{
Siti-Suhaila AR* \& Norwati M \\ Forest Research Institute Malaysia, 52109 Kepong, Selangor, Malaysia \\ *sitisuhaila@frim.gov.my
}

Submitted October 2020; accepted March 2021

\begin{abstract}
A temporary immersion bioreactor system, SETIS ${ }^{\mathrm{TM}}$, was successfully used for micropropagation of Nepenthes hybrid $(N$. viking $\times N$. miranda). Tissue culture plantlets easily wither during acclimatisation due to water loss caused by less wax formation and lack of stomatal function in leaves. Therefore, this study was aimed at improving the leaf performances and survival rate of Nepenthes. Different strengths of Murashige and Skoog (MS) liquid media, BAP (6-benzylamino purine) concentrations and immersion durations were investigated. Results showed that half strength MS medium with $0.1,0.25$ and $0.5 \mathrm{mg} \mathrm{L}^{-1}$ BAP and 5 min immersion gave $100 \%$ raft supporter coverage in SETIS ${ }^{\mathrm{TM}}$ vessels. The highest number of leaves $(16.67 \pm 1.53)$ was greater from MS medium with $0.1 \mathrm{mg} \mathrm{L}^{-1} \mathrm{BAP}$ at $10 \mathrm{~min}$ immersion, compared to control culture (between $8 \pm 1.0$ and $12 \pm 4.36$ ). The highest morphological changes in leaf (length $=$ $10.13 \pm 0.36 \mathrm{~cm}$ and width $=2.29 \pm 1.12 \mathrm{~cm}$ ) were derived from half strength MS medium with $0.25 \mathrm{mg} \mathrm{L}^{-1}$ BAP (10 min immersion), twice the size of control culture. Plants from half strength MS medium with $0.5 \mathrm{mg} \mathrm{L}^{-1} \mathrm{BAP}$ at 5 and $10 \mathrm{~min}$ immersion gave the highest survival rate $(70 \pm 0.0 \%)$ compared to control culture $(36 \pm 1.2 \%)$.
\end{abstract}

Keywords: Plant growth, survival rates, tissue culture, acclimatisation

\section{INTRODUCTION}

Currently, there are approximately 860 species from 18 genera of carnivorous plant distributed worldwide (Cross et al. 2020), with 40 species found in Malaysia (Damit et al. 2018). Many of the natural habitats of these carnivorous plant species are found concentrated in wetland areas, which are highly disturbed and degraded (Cross et al. 2020). Development, including housing and industries, is always at odds with conservation and has driven some species to near extinction. Thus, there is an urgent need to develop a reliable technique in tissue culture to help these endemic species escape extinction.

Pitcher plants (Nepenthes) are beautiful carnivorous ornamental plants. Tissue culture technique has contributed in conservation and domestication efforts of many plant species including Nepenthes, namely, N. khasiana (Rathore et al. 1991, Latha \& Seeni 1994, Bahadhur et al. 2008), N. carunculata and N. madagascariensis (Redwood \& Bowling 1990, Fay 1994). Nepenthes khasiana, an endemic to Assam Hills in India; has been successfully established in tissue culture using nodal segments with modified Murashige and Skoog (MS) medium containing combinations of plant growth regulators. As high as $80 \%$ of Nepenthes sp. shoots rooted on MS medium supplemented with $\alpha$-naphthalene acetic acid (NAA) and kinetin (Rathore et al. 1991). Latha and Seeni (1994) reported that proliferation of shoots was successfully induced using nodal segments cultured in Woody Plant Medium (WPM) supplemented with 6-benzyladenine (BA) while Bahadhur et al. (2008) reported improved results using WPM basal medium supplemented with 6-benzylamino purine (BAP) and NAA.

In vitro plantlets of $N$. carunculata and N. madagascariensis, which were produced from seedlings, successfully flowered in culture (Redwood \& Bowling 1990). Other tissue culture studies of Nepenthes species such as N. macfarlanei (Chua \& Henshaw 1999) and N. albomarginata (Sukamto et al. 2011) were conducted using more complex plant growth regulators with half strength MS medium. Nepenthes species 
found in Sarawak, Brunei and Kalimantan such as $N$. ampullaria, $N$. gracilis and $N$. rafflesiana have been propagated using seeds and stem cuttings (Sani et al. 2000). Although these studies have shown successful multiplication in vitro, failure for successful acclimatisation is a major hindering factor for conservation and commercial micropropagation of these species. Tissue culture-derived plantlets grown under low light intensity supply, aseptic conditions, sufficient nutrients and high levels of humidity experience heterotrophic growth (Hazarika et al. 2006). These conditions result in the formation of plantlets of abnormal morphology, anatomy and physiology. When shoots or plantlets are transferred from in vitro to the greenhouse, they desiccate or wilt rapidly and in some cases die because of changes in the environment, unless substantial precautions are taken to accommodate plant development (Hazarika et al. 2006). Another disadvantage of tissue culture-derived plantlets is less epicuticular layer or wax develop on the leaves, hence great water loss occur during ex vitro (Tanaka et al. 1992).

\section{MATERIALS AND METHODS}

\section{Plant materials}

In vitro culture establishment and shoot proliferation

Seedpods of $N$. viking $\times N$. miranda hybrid (NP2) obtained from the Tissue Culture Laboratory, at the Forest Research Institute Malaysia were surface-sterilised with $100 \%$ ethanol with Tween 20 ( 1 drop per $100 \mathrm{~mL}$ ) for $20 \mathrm{~min}$ followed by three rinses with sterile distilled water. Seedpods of NP2 were then blotted on sterile Whatman filter paper sheets and carefully dissected and the seeds were transferred into $30 \mathrm{~mL}$ test tubes containing $10 \mathrm{~mL}$ of MS hormone-free medium (Murashige \& Skoog 1962). The MS medium was prepared beforehand by adding $0.3 \%$ Gelrite and $3 \%$ sucrose, adjusting the $\mathrm{pH}$ to 5.8 then autoclaving at $121^{\circ} \mathrm{C}$ and $1.1 \mathrm{~kg} \mathrm{~cm}^{-2}$ for $15 \mathrm{~min}$. The seeds were cultured for two months at $25 \pm 1{ }^{\circ} \mathrm{C}$ with a 12-hour photoperiod, light intensity at 12 to $15 \mu \mathrm{mol} \mathrm{m} \mathrm{m}^{-2} \mathrm{~s}^{-1}$, and relative room humidity of under $50 \%$. Germinated NP2 seeds were then transferred into MS medium supplemented with $0.1 \mathrm{mg} \mathrm{L}^{-1}$ of BAP and incubated for six months for shoot multiplication. The shoots were then repeatedly subcultured until enough shoots were obtained for further experiments.

\section{Combination treatments}

The NP2 shoot tips (about $3 \mathrm{~cm}$ long), each with three to four nodal segments were excised from the subcultured shoots and transferred into the top compartment of the SETIS ${ }^{\mathrm{TM}}$ vessels. The vessels have raft supporters for the plants to grow and grip upon. The bottom compartment was filled with $1.5 \mathrm{~L}$ liquid media of full or half strength MS media supplemented with different concentrations of BAP $\left(0,0.1,0.25,0.5 \mathrm{mg} \mathrm{L}^{-1}\right)$ with two immersion durations ( 5 and $10 \mathrm{~min}$ ) of 2-hour intervals for each immersion. Each treatment was repeated three times. The bioreactor compartments were connected by a small tube for liquid medium movement. As compressor pumped filtered air into the bottom compartment, the liquid medium rose to the top compartment and immersed the plants. The treatments were conducted for six months and the area (\%) of raft supporter covered by shoots was recorded. The system was kept running for another two months for root development. Only complete plantlets (shoot and root developed) were transferred into pots for survival rate experiment in the greenhouse.

\section{Acclimatisation}

Plantlets of NP2 were transferred out from the temporary immersion system vessels and rinsed under running tap water to eliminate traces of liquid medium. Plantlets were immersed in fungicide $(0.1 \%$ thiram solution $)$ for $30 \mathrm{~s}$ to avoid fungal growth. The roots were then wrapped in sphagnum moss and put into small pots and placed in acclimatisation chambers in the greenhouse. Plants were kept at $25 \pm 2{ }^{\circ} \mathrm{C}$ and sprayed with water once a day. Plantlet mortality was recorded after 21 days. Plants that survived were removed from the chambers and transferred into bigger pots containing leica and sphagnum moss for further growth in the greenhouse.

\section{Statistical analysis}

The average percentages of raft supporter area covered by shoots were compared between the 
treatment combinations after six months in culture. Average percentages of number of leaves, leaf length, leaf width and root length were recorded after eight months in the same culture. The percentages of survival for plants after 21 days of acclimatisation period were compared to plants grown in glass jars (control).

\section{RESULTS AND DISCUSSION}

\section{Shoot development in SETIS ${ }^{\mathrm{TM}}$}

The NP2 shoot tips cultured on BAPsupplemented media in the SETIS ${ }^{\mathrm{TM}}$ started to show growth after three to four weeks, with many small leaves produced at the petiole region. There were no calli and embryonic tissues observed in any treatment. By the end of the four months in culture, NP2 shoots from half strength MS combination treatments produced more and larger leaves compared with full MS liquid media (Table 1). It is the nature of carnivorous plants to inhabit nutrient-poor habitats, which will promote better pitcher development (Adamec 1997). The results showed that three treatments gave $100 \%$ raft supporter coverage. These were are half strength MS liquid medium ( 5 min immersion) with 0.1 (T11), 0.25 (T13) and 0.5 (T15) $\mathrm{mg} \mathrm{L}^{-1}$ BAP (Table 1). In the control cultures, half strength MS liquid medium performed better than full strength. Results showed half strength MS liquid medium at 5 min immersion (T9) resulted in $87.5 \%$ raft supporter coverage, followed by full strength MS liquid medium (77.1\%) at 5 min immersion (T1), half strength MS liquid medium (32\%) at 10 min immersion (T10) and full strength MS liquid medium (16\%) at $10 \mathrm{~min}$ immersion (T2). The highest leaf number $(16.67 \pm 1.53)$ was observed in full MS liquid medium with $0.1 \mathrm{mg} \mathrm{L}^{-1} \mathrm{BAP}$ with $10 \mathrm{~min}$ immersion (T4) (Table 1), followed by half strength MS liquid medium $(15.00 \pm 4.73)$ with $0.5 \mathrm{mg} \mathrm{L}^{-1}$ BAP for $5 \mathrm{~min}$ immersion. As for control cultures, both full and half strength MS media produced lesser number of leaves than those supplemented with BAP. The control cultures from full strength treatments (T1 and T2) produced $12.0 \pm 4.36$ and $10 \pm 2.0$ number of leaves at 5 and $10 \mathrm{~min}$ immersion respectively. Control cultures from half strength MS liquid medium treatments (T9 and T10) produced lesser number of leaves than control from full strength, with $9.0 \pm 0.58$ at 5 min immersion and
$8.00 \pm 1.00$ at $10 \mathrm{~min}$ immersion. Nepenthe khasiana had a higher number of shoots $(19.16 \pm 0.23)$ with more complex medium of half strength MS agar medium supplemented with $2.5 \mathrm{mg} \mathrm{L}^{-1}$ kinetin and $2 \mathrm{mg} \mathrm{L}^{-1}$ BAP (Soibam et al. 2013).

In this study, the biggest leaf size in NP2 was derived from treatment with half strength MS liquid medium supplemented with $0.25 \mathrm{mg} \mathrm{L}^{-1}$ BAP at 10 min immersion per cycle. The control cultures also showed leaves produced from half strength MS liquid media treatments were longer than full strength with $10 \mathrm{~min}$ immersion. The half strength MS liquid medium from treatments T9 and T10 gave leaf lengths of $6.41 \pm 1.97 \mathrm{~cm}$ and $7.11 \pm 1.46 \mathrm{~cm}$ respectively. The leaf number from full strength MS liquid medium from $\mathrm{T} 1$ and $\mathrm{T} 2$ were lesser than control from half strength MS liquid medium with $5.29 \pm 1.06$ and $5.30 \pm 0.94$ respectively. The longer and broader leaves were due to the bigger SETIS $^{\mathrm{TM}}$ vessel size (up to $3000 \mathrm{~mL}$ ) compared with conventional method of using $50 \mathrm{~mL}$ agar medium in a glass jar. Incubating plant material in liquid-shaken cultures increases the rate of shoot proliferation in some non- carnivorous plant species $(\mathrm{Hu} \&$ Wang 1983). Under reduced humidity level, cultured Chrysanthemum plantlets demonstrated the establishment of functional leaves with the ability to fully expand, characterised by typical deposition of surface wax and responsive stomata (Ritchie et al. 1991). Their work demonstrated that cultured plants needed to be exposed to a reduced relative humidity of about $81 \%$ during the initial stages of culture. The SETIS ${ }^{\mathrm{TM}}$ system we used which incorporated humidity fluctuation, not only facilitated stomatal function but also induced the in vitro production of wax for better adaptation to ex vitro conditions later on. These studies therefore indicated that plantlets could be acclimatised in vitro by reducing the humidity of the culture vessel.

Tanaka et al (1988) has developed a disposable fluorocarbon polymer film culture vessel, which is gas permeable and facilitates reduction in the relative humidity normally found in culture flasks. When humidity was reduced in vitro, Chrysanthemum plantlets was successfully transferred from culture vessels to soil conditions without wilting (Smith et al. 1990). In this study, NP2 plantlets from SETIS ${ }^{\text {TM }}$ were continuously exposed to microenvironment as the environment outside will minimise the stress experienced by the plants when 


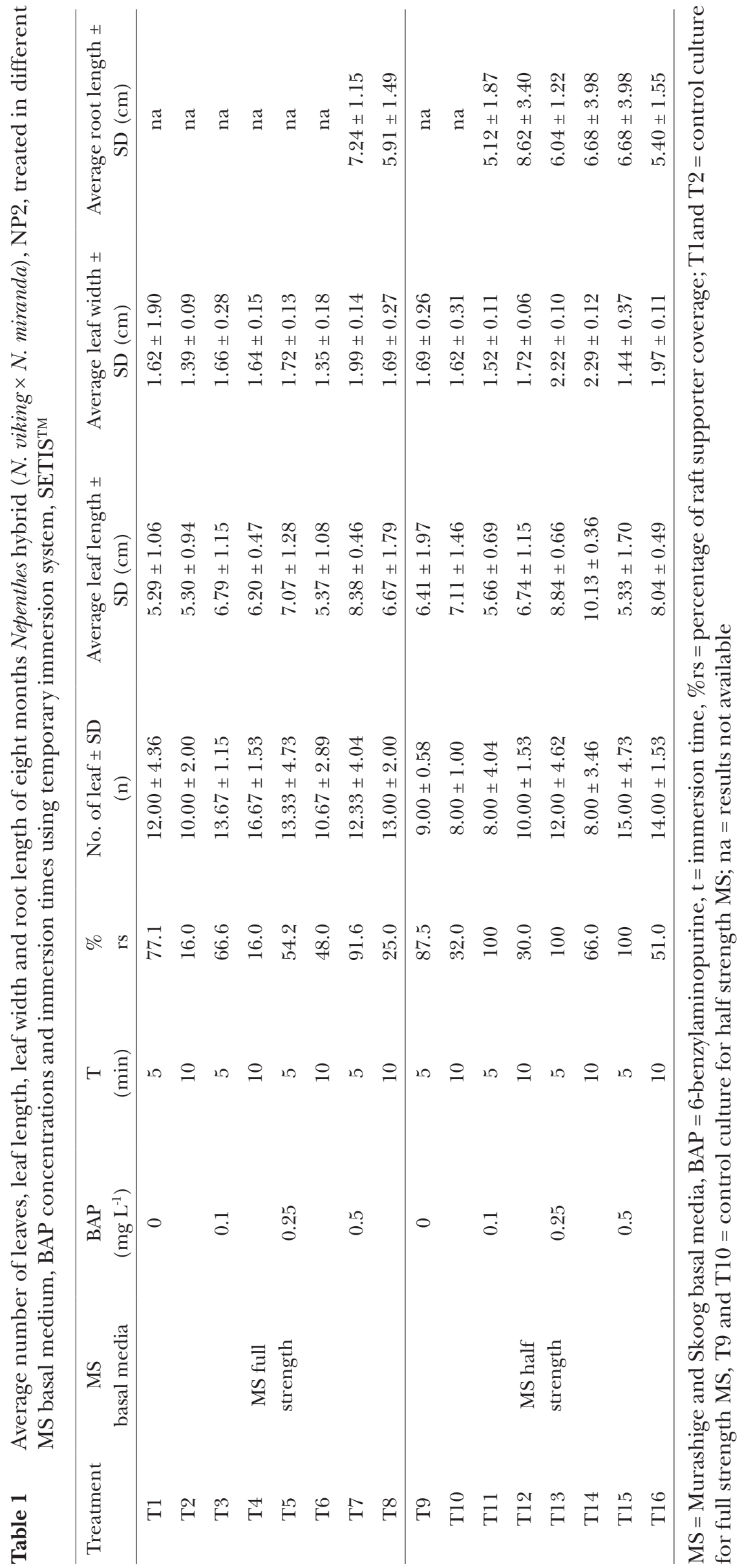


transferred to the greenhouse. Micropropagation vessels named RITA $^{\circledR}$, also a type of temporary immersion system (TIBs), effectively acclimatise plantlets in vitro without the need for post ex vitro acclimatisation (Kosky et al. 2015). These vessels allow for gaseous exchange, eliminate negative effects of ethylene accumulation and remove abnormal morphologies associated with hyperhydricity.

By the end of six months in culture, more than $40 \%$ of the combination treatments successfully cover $100 \%$ of the vessel. Few treatments, however, reached certain points of development in cultures and plateau similar to the observations in control cultures, with $30-40 \%$ raft supporter coverage. By the end of the eight months, only $50 \%$ of the treatments were able to produce roots in NP2 without auxin (root inducer), and these were mainly observed in half strength MS liquid medium combination treatments. Nepenthes khasiana root development was faster after 21 days in culture with the addition of root growth regulator, NAA $\left(0.05\right.$ to $\left.2 \mathrm{mg} \mathrm{L}^{-1}\right)$ (Bahadhur et al. 2008). In this study, the ability for NP2 plants to produce roots in vitro without auxin in bottles (control cultures) and SETIS ${ }^{\mathrm{TM}}$ (Figure 1), is an advantage for lower media cost in tissue culture. Nevertheless, leaves of cultures from the bottles wilted immediately during plant transfer into acclimatisation chamber whereas plantlets from SETIS ${ }^{\mathrm{TM}}$ experience minor wilting during the same period of time. In this study, SETIS $^{\text {TM }}$ improved the plant ability to adapt to normal environment due to the ventilation system incorporated to the vessels which caused fluctuation of humidity inside the vessels. This fluctuation enhanced stomatal functioning, and possibly, the epicuticular layer on the leaf. If less epicuticular layer or wax develop on leaves, there will be greater water loss during ex vitro
(Tanaka et al. 1992). Precaution must be taken when potting plantlets to accommodate plant development and avoid desiccation or rapid wilt leaf or even death due to changes in the environment (Hazarika et al. 2006).

\section{Survival rates}

The NP2 plantlets from SETIS ${ }^{\mathrm{TM}}$ were observed side by side with plantlets from semisolid medium (control). The observation showed that during the earlier stage of acclimatisation, mortality rates occurred by the third day in plantlets from control cultures and reached $50 \%$ by the ninth day. Plantlets from SETIS ${ }^{\mathrm{TM}}$ showed strong and healthy plants and only experienced minor microenvironment changes during the first week of acclimatisation and quickly recovered and produced new leaves.

By the end of the 21 days, about $36 \%$ of plantlets from control cultures survived and survival of plantlets from SETIS ${ }^{\mathrm{TM}}$ remained at $70 \%$ throughout the acclimatisation period (Figure 2). Humidity fluctuations inside SETIS ${ }^{\mathrm{TM}}$ vessels encouraged the stomata to function even in in vitro conditions. Therefore, the plants were prepared ahead of acclimatisation and did not lose too much water in their cells and were able to develop further in the current environment. On the other hand, the $100 \%$ humidity condition inside the glass jar (control) made the plants unable to adapt quickly to the environment (Figure 3). Thus, the leaf became wilted due to high water loss.

\section{CONGLUSIONS}

This study showed that SETIS ${ }^{\mathrm{TM}}$ was a suitable TIBs for enhancement of leaf size and survival rate in Nepenthes hybrid ( N. viking $\times N$. miranda).
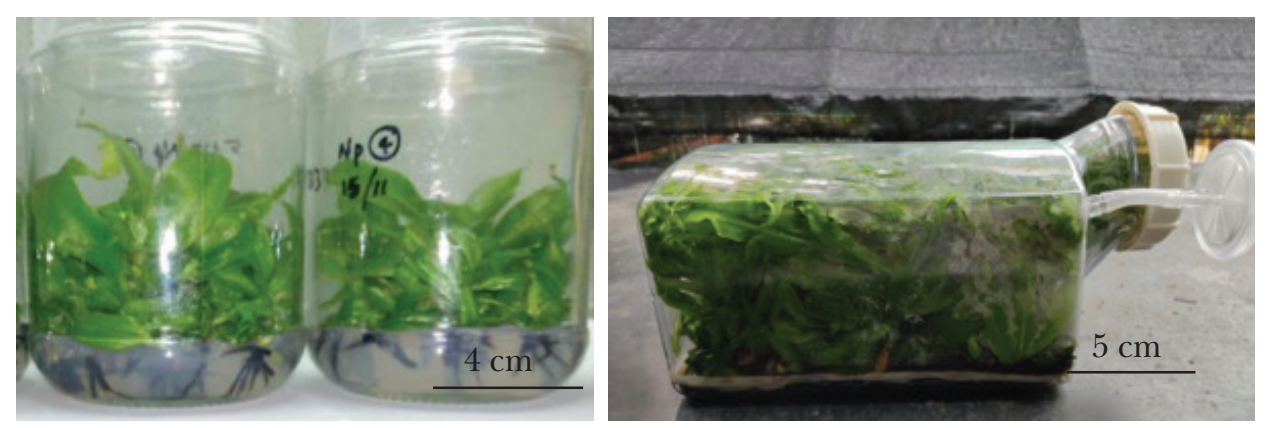

Figure 1 Nepenthes hybrid $(N$. viking $\times N$. miranda), NP2, grown in different containers: (left) bottle (close system) and (right) SETISTM (open system) 


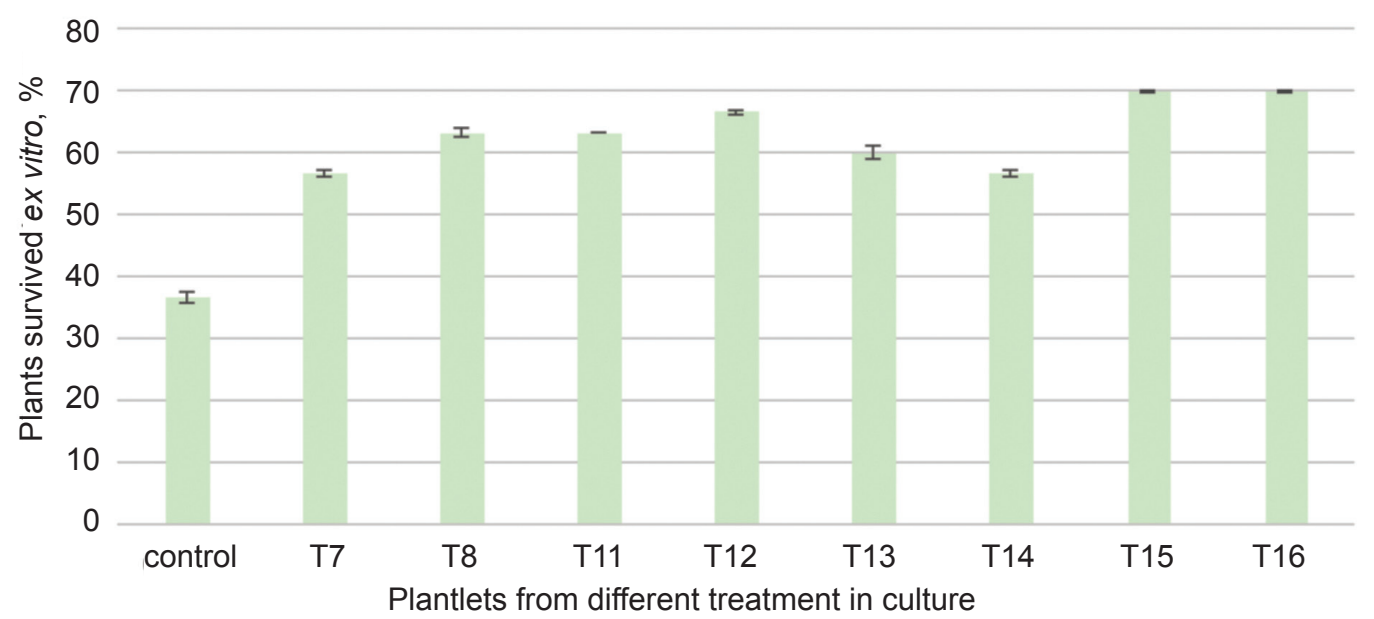

Figure 2 Average survival percentage $( \pm \mathrm{SD})$ from rooted Nepenthes hybrid (N. viking $\times$ N. miranda) after 21 days of acclimatisation; treatments T7-T8 and T11-T16 = NP2 plantlets treatments using SETIS ${ }^{\mathrm{TM}}$, control = treatment using semisolid medium
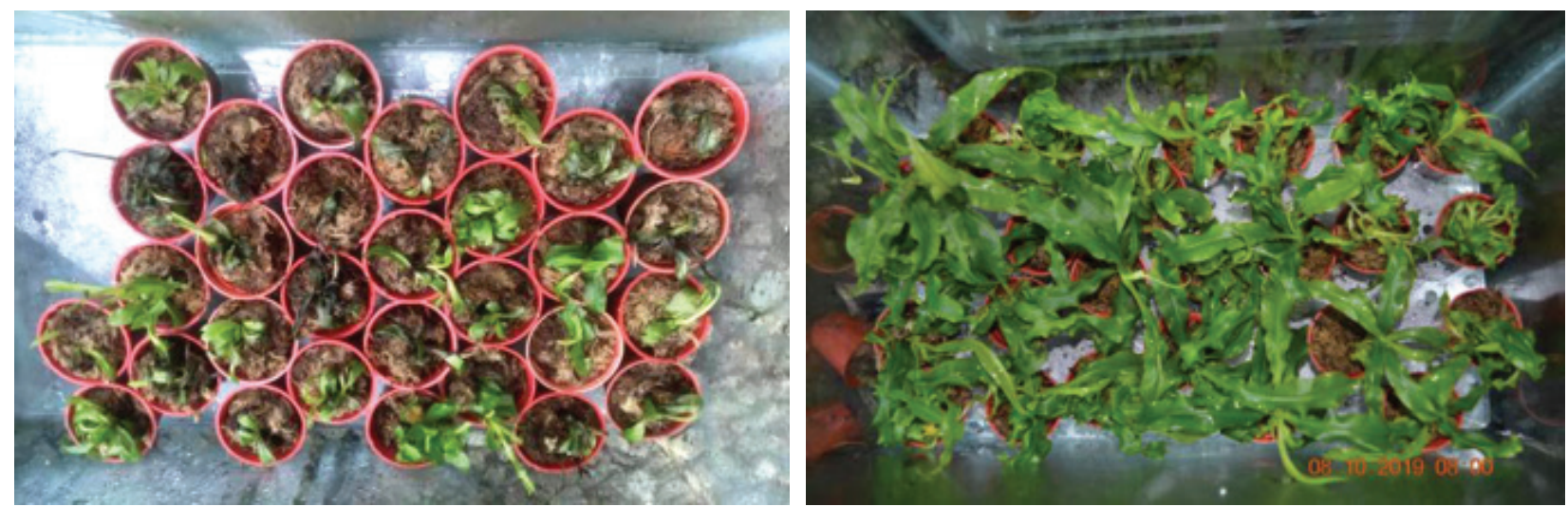

Figure 3 Condition of plantlets after 21 days acclimatisation: (left) plantlets from semisolid medium (control culture) and (right) plantlets from SETIS ${ }^{\mathrm{TM}}$

The open system concept in TIBs facilitated the production of high quality plantlets and higher survival rate, which could be applied to other Nepenthes species. The technology is not only useful for production of highly commercialised Nepenthes plants but can also play a role in conservation of plants that are near extinction by alleviating collection pressure in the wild. Further investigation on plant multiplication rate, immersion time and incubation time before potting to greenhouse needs to be carried out for faster plant production.

\section{ACKNOWLEDGEMENTS}

We would like to thank the Ministry of Energy and Natural Resources and FRIM (RMK11) for funding this project. Our gratitude goes to staff of the Center for Biotechnology
Bioenterpreneur, namely, Normah B, Mohamad Fitri O, Nurnadiah R, Noor Ratul M and Mohd Syahiran $\mathrm{S}$ for their contribution and efforts in the project.

\section{REFERENCES}

Adamec L. 1997. Mineral nutrition of carnivorous plants: a review. The Botanical Review 63: 273-299.

Bahadhur V, Kirad KS, Mathew A \& Singh DB. 2008. Tissue culture studies in Nepenthes khasiana. Acta Horticulturae 786: 287-293. ttps://doi.org/10.17660/ ActaHortic.2008.786.35

Chua LSL \& Henshaw G. 1999. In vitro propagation of Nepenthes macfarlanei. Journal of Tropical Forest Science 11: 631-638.

Cross AT, Krueger TA, Gonella PM, Robinson AR \& FLeISCHMANN AS. 2020. Conservation of carnivorous plants in the age of extinction. Global Ecology and Conservation. 24: e01272. http://doi.org/10.1016/j. gecco. 2020 
Damit A, Sugau JB, Nilus R \& Suleiman M. 2018. Nepenthes species of Mount Trus Madi in Sabah Borneo. Paper presented at Conference of 18th Malaysian Forestry Conference. 31 July-2 August 2018, Kuching.

FAY MF. 1994. In what situation is in vitro culture appropriate to plant conservation? Biodiversity and Conservation 3: $176-183$.

Hazarika BN, Teixeira DA, Silva Ja \& Talukdar A. 2006. Effective acclimatization of in vitro cultured plants: methods, physiology and genetics. Pp 427-438 in da Silva JAT (eds) Floriculture, Ornamental and Plant Biotechnology: Advances and Topical Issues. Volume 2. Global Science Books, Middlesex.

Hu CY \& WANG PJ. 1983. Meristem, shoot tip and bud cultures. Pp 177-227 in Evans DA et al. (eds) Handbook of Plant Cell Culture. Macmillan Publishing Co., New York.

Kosky R, Perozo J, Valero N \& Penalver D. 2015. Somatic embryos germination of Psidium guajava $\mathrm{L}$. in the Rita ${ }^{\circledR}$ temporary immersion system. Pp 225-229 in Hvoslef-Eicle AK \& Preil W (eds) Liquid Culture Systems for In Vitro Plant Propagation. Springer, Dordrecht.

LATHa PG \& SEENI S. 1994. Multiplication of the endangered Indian pitcher plant (Nepenthes khasiana) through enhanced axillary branching in vitro. Plant Cell, Tissue and Organ Culture 38: 69-71.

Murashige T \& Skoog F. 1962. A revised medium for rapid growth and bioassays with tobacco tissue cultures. Physiologie Plantarum 74: 473-497.

Rathore TS, Tandon P \& Shekhawat NS. 1991. In vitro regeneration of pitcher plant (Nepenthes khasiana)-a rare insectivorous plant of India. Journal of Plant Physiology 139: 246-248.
Redwood GN \& Bowling JC. 1990. Micropropagation of Nepenthes sp. Royal Botanic Gardens Micropropagation News 1: 19-20.

Ritchie GA, Short KC \& Davey MR. 1991. In vitro acclimatization of Chrysanthemum and sugar beet plantlets by treatment with paclobutrazol and exposure to reduced humidity. Journal of Experimental Botany 42: 1557-1563.

Sani BH, Meekiong K, Lee WW \& Dayang Awa AL. 2000. Vegetative propagation of selected Nepenthes species. Borneo Science 7: 1-9.

Smith EF, Roberts A \& Mottely J. 1990. The preparation in vitro of Chrysanthemum for transplantation to soil-3. Improved resistance to desiccation conferred by reduced humidity. Plant Cell, Tissue and Organ Culture 21: 141-145. doi: 10.1007/BF00033433

Soibam PD, Suman K, Rao SR \& Tandon P. 2013. In vitro propagation and assessment of clonal fidelity of Nepenthes khasiana Hook. f.: a medicinal insectivorous plant of India. Acta Physiologiae Plantarum 35: 2813 2820. https://doi.org/10.1007/s11738-013-1314-x

Sukamto LA, Mujiono M, Djukri D \& Henuhili V. 2011. In vitro shoot tip culture of Nepenthes albomarginata Lobb ex Lindl. Jurnal Biologi Indonesia 7: 251-261.

Tanaka K, Fujiwara K \& Kozai T. 1992. Effects of relative humidity in the culture vessel on the transportation and net photosynthesis rates potato plantlets in vitro. Acta Horticulturae 319: 59-64.

Tanaka MK, Jinno K, Goi M et al. 1988. The use of disposable fluorocarbon polymer film culture vessel in micropropagation. Acta Horticulturae 230: 73-80. 